\title{
Primary Health Care Challenges in Rural/Remote Areas of Yakutia and Use of Automated Systems for the Medical Screening Examination of the Pediatric Population
}

\author{
Sardana A. Evseeva ${ }^{1 *}$, PGS; Vyacheslav G. Chasnik ${ }^{1}, \mathrm{PhD}, \mathrm{ScD}$; \\ Tatiana E. Burtseva ${ }^{2 *}, \mathrm{PhD}, \mathrm{ScD}$; Maya S. Savvina ${ }^{2}, \mathrm{PhD}$; \\ Fecla V. Vinocurova ${ }^{1}$, PGS

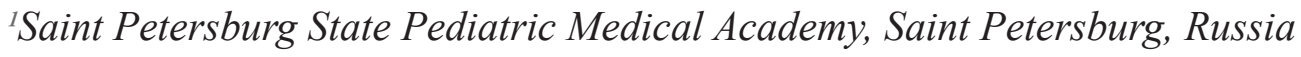 \\ ${ }^{2} Y a k u t s k$ Research Center for Complex Medical Problems, Yakutsk, Sakha Republic, Russia
}

\begin{abstract}
The negative consequences of social and economic changes in recent decades have primarily affected the rural population and violated the main principles of medical care organization for this group. The reduction by one third in the number of district hospitals, uncompensated by adequate development of outpatient care, and a shortage of doctors in rural clinics led to reduced availability of primary care. Specialized medical assistance in regional and national hospitals has also become less accessible to the rural population due to the high cost of travel. The number of doctors and nurses in rural areas is lower by 3.4 and 1.6 times, respectively, than in cities. In this regard, the burden and responsibility for rural health workers is much higher.

Study of the opinions of the medical staff of the Northern and Arctic regions is an important part of the decision-making system in health care, allowing us to carry out modernization programs in the industry and increase their efficiency through feedback mechanisms. This article presents the available data on the problems of organizing medical assistance for residents of the Northern and Arctic regions of Yakutia, because dealing with these problems is still the most socially significant task for the authorities and carries a great load of negative experience, stereotypes, and scientific-methodological errors.

To assess the quality of medical care, we conducted an anonymous survey of parents and medical staff of the Northern and Arctic regions of Yakutia. A total of 1,415 parents and 322 health specialists were interviewed between 2011 and 2012. The results of the anonymous survey revealed that in the Northern and Arctic regions of Yakutia there is a deficit of qualified specialists of different profiles, an unsatisfactory infrastructure of medical offices and hospitals, and a low level of income for medical personnel and the whole population. All above listed are some of the reasons for developing and implementing health care information technologies to improve the quality of medical services in remote settlements of Yakutia. (Int J Biomed. 2015;5(4):224-227.)

Keywords: healthcare; Yakutia; automated medical examinations, children's health; quality of diagnosis.
\end{abstract}

\section{Introduction}

Yakutia (the Sakha Republic) is the largest subject of the Russian Federation; Yakutia occupies one-fifth of Russia. It is one of the coldest regions in the world. The average annual amplitude of air temperature is over $100^{\circ} \mathrm{C}$. According to the Russian State Statistics Committee (2013), Yakutia has a

*Corresponding authors: Tatiana E. Burtseva, PhD, ScD. Deputy Director of the Yakutsk Research Center for Complex Medical Problems, Yakutsk, Russia.E-mail: bourtsevat@,rambler.ru

Sardana A. Evseeva, Postgraduate Student of Saint Petersburg State Pediatric Medical Academy, Saint Petersburg, Russia.

E-mail:sarda79@mail.ru population of 955,580 people; the population density of the republic is 0.32 persons per $1 \mathrm{~km}^{2}$, while in a number of the Arctic regions, it ranged from 0.1 to 0.01 persons per $1 \mathrm{~km}^{2}$. About $40 \%$ of the territory lies above the Arctic Circle, where only $7 \%$ of the population lives, including the indigenous peoples of the North who lead a traditional nomadic way of life. Russia has 40 small ethnic groups that are officially classified as "indigenous small-numbered peoples of the North, Siberia and the Far East". Demographic information is available on twenty-six ethnicities, of which approximately 91,000 live north of the Arctic circle, and 70,000 inhabit sub-Arctic territories north of the 60th parallel. Nearly three quarters of the indigenous minority people live in rural areas 
( $80 \%$ in the Arctic) and are dispersed across vast territories. All these factors have a certain impact on the medical aid organization for the population $[1,2,3]$.

Currently, Yakutia consists of 36 municipalities, including 34 municipal regions, 2 urban districts, 55 urban settlements, and 586 rural settlements. One-third of the population lives in rural areas; $50 \%$ of 676 settlements belong to the category of sparsely populated, $44 \%$ to the category of hard-to-reach and remote, and 12 districts have a population below ten thousand [4].

More than ninety percent of the Republic's territory is in the area of seasonal transport service, where communication is mainly by air, water and road (seasonal). Thus, $76 \%$ of 34 districts do not have reliable transport links with the center of the Republic and surrounding regions. The most remote village is situated at a distance of $3,189 \mathrm{~km}$ from Yakutsk, and in the interior, the distance from the medical centers to the Central District Hospital averages about $400 \mathrm{~km}$ and yeararound travel is not possible. Almost $90 \%$ of local roads do not meet regulatory requirements. In Yakutia, there are 580 health agencies, including 20 republican institutions. Currently, in Yakutia, as in many regions of Russia, an unstable situation has been formed regarding medical personnel. Eight hundred and twenty-five doctors and 3,146 nursing staff work in health care facilities serving the rural population. During 2012, the number of doctors decreased by 38 people $(0.8 \%)$, staff nurses by 103 people $(0.9 \%)$. The ratio of the staff units (doctors:nurses) was $1: 2.2$. The coefficient of secondary occupations was 1.4 for doctors and 1.3 for nursing staff. The total number of salaried professional positions was 5,614 for doctors and 12,014 for nurses. In the healthcare system, vacant positions totaled up to 131.25 for the doctors and 114.5 for the nurses. The low physician staffing is a main problem for the Arctic regions.

In some regions of the Arctic zone, physician staffing does not reach 50\%: for example, $49 \%$ in Allaikhovskiy, $49.4 \%$ in Verhojansk, $48 \%$ in Lower Kolyma, $47.8 \%$ in Oymyakon, and $46.6 \%$ in Ust-Yana. The increased migration of the population and departure of specialists outside the Republic affects very negatively the provision of medical services by medical personnel. In recent years, the number of retired doctors was approximately equal to the number received to work in health institutions. Thus, in 2012, 627 doctors left their posts: $115(13.7 \%)$ were due to natural decline and 428 to self-request and translocation. Newly arrived doctors amounted to 589 .

The present situation with staff shortages and the low capacity of medical institutions leads to a lower quality of medical care in the remote and inaccessible locations of Yakutia.

\section{Materials and Methods}

To assess the quality of healthcare in Yakutia, we conducted an anonymous survey of parents and medical workers living in this region in 2012. In particular, we conducted an anonymous survey of parents living in 16 districts (Upper Kolyma, Lenskiy, Tomponskiy, Srednekolymskiy, Amginskiy, Verhnevilujskiy, Neryungrinskiy, Ust-Yanskiy, Ust-Maisky,
Verkhoyanskiy, Aldanskiy, Olekminskiy, Suntarskiy, UstAldaniy, Namskiy, Megino-Kangalasskiy) to determine the factors influencing the quality of medical care in remote settlements; 1,415 questionnaires were filled out. We also conducted an anonymous survey of medical workers living in 17 districts of Yakutia (Mirniy, Khangalasskiy, Zhiganskiy, Abyiskiy, Aldanskiy, Amginskiy, Neryungrinskiy, Namskiy, Suntarskiy, Kobyayskiy, Olekminskiy, Verhnevilujskiy, Olenekskiy, the Upper Kolyma, Ust-Mayskiy, Verkhoyanskiy, and Yakutsk) to evaluate their professional opinion on the state of rural health care; 322 questionnaires were filled out.

The next phase of the study was devoted to the organization of a pilot project on the implementation of automated medical examinations (ACE), namely, AKDO system in the Olenek district of Yakutia. AKDO systems for prophylactic examination of children are designed to provide comprehensive quantitative assessment of the state of health based on the aggregate of initial medical parameters obtained during prophylactic examination [5]. New models of AKDO system implement an extended range of instrumental examination. They provide:

- ECG with the 12- channel Valenta electrocardiograph

- Rhythmography

- Bicycle ergometry

- Phonocardiography

- Rheography

- Spirometry.

Modern AKDO systems consist of individual structural units designed to solve specific diagnostic problem. The number of pathology profiles screened by individual units may reach 300. AKDO systems provide quantitative comparative analysis of diagnostic data obtained at different periods of time or in different places.

The study was approved by the Yakutsk Research Center for Complex Medical Problems Ethics Committee. Written informed consent was obtained from the child's parents.

\section{Results and Discussion}

The results of data analysis of questionnaires were unexpected: on average, $88.3 \%$ of the respondents (the rural residents) were not satisfied with number of local medical offices: $63.5 \%$ of the residents of settlements nearest to the district center, $73.3 \%$ of the residents of the farthest settlements, and $92.8 \%$ of the residents of the remote and inaccessible localities.

According to the survey of parents, among the main reasons for the low quality of care was the lack of qualified specialists of different profiles (88.2\%) and poorly equipped medical offices $(71.7 \%)$. Lack of necessary medications, low qualification of the physicians, and expensive medications were noted in $60.2 \%, 39.8 \%$, and $36.6 \%$ of cases, respectively.

One of the problems of rural health care in Yakutia is the poor availability of specialized and high-tech medical care. According to the respondents, they are unable to attend an examination or treatment in the district hospital during the spring and autumn thaw due to the lack of roads or, in summer, poor road conditions $(36.2 \%)$. Other barriers are lack of money 
for travel (34\%), duration of travel (about 8-10 hours) to the district center (23.7\%), and lack of transport (6.1\%).

For example, one question asked, «How often do you visit the doctor to get information about your general health?» Sixty percent of respondents replied «rarely,» 36.4\% "constantly,» and 3.6\% «never.» To the question «To what purpose do you usually visit a doctor?" overall, $71.2 \%$ of the respondents replied «for treatment,» $16.7 \%$ «for clinical examination,» $4.5 \%$ «for dispanserization," and $1.7 \%$ "for preventive examinations." Respondents indicated the greatest need $(75.4 \%)$ was for such specialists as a cardiologist, a neurologist, an ophthalmologist, and an otolaryngologist.

An anonymous survey of health staff working in the pediatric service of Yakutia revealed a number of negative health and social factors. Overall, $80.6 \%$ health workers are not fully satisfied with the quality of care in their healthcare setting. According to the respondents, the following factors influence their work: deficit of qualified specialists of different profiles $(71.5 \%)$, poorly equipped medical offices $(59 \%)$, lack of necessary medications $(41.6 \%)$, and low level of physician and nurse staffing $40.1 \%$ and $19.7 \%$, respectively). Most medical professionals $(85.9 \%)$ consider that an outpatient medical record takes longer time than an examination of a child. Overall, $70.4 \%$ of respondents note the lack of cooperation between the family doctors, the staff of the school and preschool departments, and the qualified specialists of different profiles.

According to the respondents, $12.5 \%$ said that during the last 5 years the healthcare system in the districts has worsened, $48.5 \%$ that it has not changed, and only $39 \%$ that it has improved. Only $39.8 \%$ of the health staff is satisfied with their work. The majority of health professionals are not completely satisfied with their work due to a lack of time for self-education, low wages, and poor equipment in medical offices.

Based on the foregoing, the next phase of the study was devoted to the organization of a pilot project on the implementation of AKDO system to improve the quality of the medical examination of children in the Olenek district of Yakutia. AKDO systems belong to such equipment designed for early-diversified diagnostics of chronic diseases made within comprehensive examinations of children, i.e. a state program of regular medical check-ups of children [5].

The population of the Olenek district is 4,028 residents (2,679 adults and 1,349 children). The Olenek district consists of four villages. The purchased AKDO complex was directed to the different villages on schedule. In general, AKDO examinations were done as follows: A trained physician teaches the nurses or medical assistants how to perform an AKDO examination. The examination of one child takes about 20-25 minutes. AKDO conclusions are transferred from big and small villages to the doctor responsible for AKDO analysis at the Central District Hospital.

Currently in Russia, AKDO examination is voted as the most convenient for healthcare facilities with a small number of specialists to conduct the combined screening-diagnostic functions of the first stage. In the second stage of our project, a pediatric center specialist visited children in their place of residence to provide diagnostic and therapeutic services, taking into account the identified pathology profiles. The third stage was an expedition of the equipped mobile medical surgical team to the children's places of residence to provide specialized medical care (MoH order No.01-8/4-378 from 07.03.2012).

As shown in Table 1, cardiovascular and rheumatologic diseases together occupy first place (92.8\%), followed by pathology of the endocrine system $(50.3 \%)$, organs of vision (40.4\%), dental disease (36.7\%), and pathology of the respiratory system $(21 / 1 \%)$, etc.

Table 1.

Prevalence of somatic diseases in child population of the Olenek district of Yakutia

\begin{tabular}{|l|c|c|c|c|}
\hline \multicolumn{2}{|c|}{ Variable } & \multicolumn{3}{c|}{ Surveyed children } \\
\cline { 3 - 5 } \multicolumn{2}{|l|}{} & $\begin{array}{c}\text { Total } \\
(\mathrm{n}=166)\end{array}$ & $\begin{array}{c}\text { Boys } \\
(\mathrm{n}=82)\end{array}$ & $\begin{array}{c}\text { Girls } \\
(\mathrm{n}=84)\end{array}$ \\
\hline Health children & $(\mathrm{n})$ & 2 & 0 & 2 \\
\hline $\begin{array}{l}\text { Children with different } \\
\text { pathology profiles }\end{array}$ & $(\mathrm{n})$ & 164 & 82 & 82 \\
\hline $\begin{array}{l}\text { cardiovascular and reumatic } \\
\text { diseases }\end{array}$ & $(\%)$ & 92.8 & 92.7 & 92.9 \\
\hline endocrine system & $(\%)$ & 51.2 & 56.1 & 46.4 \\
\hline organs of vision & $(\%)$ & 40.4 & 36.6 & 44.0 \\
\hline dental disease & $(\%)$ & 36.7 & 36.6 & 36.9 \\
\hline respiratory system & $(\%)$ & 21.1 & 24.4 & 17.9 \\
\hline nervous system & $(\%)$ & 20.5 & 26.8 & 14 \\
\hline allergy & $(\%)$ & 13.3 & 14.6 & 11.9 \\
\hline orthopedic pathology & $(\%)$ & 12.0 & 18.3 & 6.0 \\
\hline otolaryngology disorders & $(\%)$ & 11.4 & 13.4 & 9.5 \\
\hline gastrointestinal pathology & $(\%)$ & 7.2 & 7.3 & 7.1 \\
\hline
\end{tabular}

In the North, the incidence of health disorders among children is considerably higher than the national average and has increased in the past decade, as up to $70 \%$ of children suffer from health disorders [3]. Our early research showed that the overall prevalence of disease in children living in indigenous minority settlements in northern Yakutia was 117 cases per 100 children examined. Among Yakut and Russian children, the rate was 131 cases per 100 children; among children from indigenous minority groups of the North, it was 108 cases per 100 children.

The prevalence of disease in a particular region depends on the region's current level of access to health care [6]. Since the description of the child's condition in terms of AKDO includes the complaints and symptoms that can be recorded even on a pre-medical level, a wide involvement of nurses to perform AKDO surveys of children living in small villages seems reasonable and advisable.

\section{Conclusion}

Development of the concept of a comprehensive medical examination of a large number of children in a short period 
of time, limited by the ability to involve highly qualified specialists only for a short time, determines the need for prequalification of the diagnostic problems to plan a rational medical examination [6-8]. Implementation of the structured approaches for the screening and diagnosis of childhood disease using modern automated technologies would make it possible to solve a number of difficult problems in the remote and inaccessible locations of Yakutia:

-improve early detection of diseases among children and adolescents

- organize standardized monitoring of children's health

- organize monitoring of the curative activity in medical institutions

-allocate healthcare resources judiciously and appropriately

-perform the development of healthcare system structure appropriately and efficiently.

\section{Competing interests}

The authors declare that they have no competing interests.

\section{References}

1. Petrova PG, Borisova NV. Environment Features and Human Health in the North. Int J Biomed. 2014;4(2):114-116.

2. Agadzhanian NA. Human adaptational physiology and ecology: culture, morality, and spirituality. Fiziol Zh 2011; 57(5):23-5. [Article in Russian].

3. United Nations in the Russian Federation. Climate Change Impact on Public Health in the Russian Arctic (2008) http:// www.unrussia.ru/sites/default/files/doc/Arctic-eng.pdf

4. Gorokhov AC, Fedotov SF. Implementation of modern information systems in healthcare of the Republic of Sakha (Yakutia). Information Technologies in the Health System. Yakutsk, 2012:10-11.

5. Vorontsov IM, Matalygina OA, Shapovalov VV. Evolution of the automated system for preventive examination of children an automated unit for mass screening examinations. Med Tekh. 2005;3:18-21. [Article in Russian].

6. Burtseva TE, Uvarova TE, Tomsky MI, Odland JØ. The health of populations living in the indigenous minority settlements of northern Yakutia. Int J Circumpolar Health. 2014 Oct 30; 73. doi: 10.3402/ijch.v73.25758. eCollection 2014. 7. Buortseva TE, Tomski MI, Verbitskaya GG, Kanaeva GG, Chasnik VG, Nikolaeva LA, et al. Assessment of the child population's health status in places of compact residence of indigenous peoples of the North in Ust-Yanskiy, Srednekolymskiy, Allaikhovskiy and Lower Kolyma regions of the Republic of Sakha (Yakutia). Proceedings of the scientific-practical conference "Children's Health in the North". Yakutsk, 2008:7-9.

8. Vorontsov I M, Shapovalov VV, Sherstyuk YM. Creation and using of automated systems for monitoring and screening diagnosis of health disorders. SPb.: ed. «Costa», 2006. 